\title{
CYBER-COLLECTIVE ACTION NETIZEN MELALUI MEDIA SOSIAL TWITTER DENGAN HASTAG \#SHAMEONYOUSBY
}

\author{
Fat'khah Dwi Hinggarwati, Pamerdi Giri Wiloso, Dewi Kartika Sari \\ Program Studi Ilmu Komunikasi \\ Fakultas Ilmu Sosial dan Komunikasi Universitas Kristen Satya Wacana \\ Email : hinggar1410@gmail.com, girindra abhiyoga@yahoo.co.id, dewikaes@gmail.com
}

\begin{abstract}
:
People use social media to communicate with others, including to give an opinions. And in this way netizen on Indonesia in giving his opinion. Netizen in Indonesia giving a protest against the government through social media twitter. They wrote the disappointment tweetwith hastag \#ShameOnYouSBY. This research use qualitative descriptive analysis, and discuss about the form of cyber-collective action that occurs in a protest the netizen, and how social media activism get the support. Of research results, obtained four stages cyber-collective action that is the individual perspective, group perspective, national perspective, and transnational perspective.In addition, social media activist also uses the principle of consumption of contemporary culture in seeking the support of the masses from social media twitter.
\end{abstract}

Keywords: Social Media, twitter, cyber-collective action, activist

\section{Pendahuluan}

Pada tanggal 26 September 2014, pemerintah menetapkan RUU Pilkada menjadi sebuah undang-undang yang di dalamnya berisi tentang kesepakatan pemilihan kepala daerah berada di tangan DPRD, dan tidak lagi berada pada pilihan rakyat.Dalam pelaksanaan sidang sempat diwarnai dengan keluarnya (walkout) anggota Partai Demokrat, yang merasa kecewa karena usulannya tidak masuk kedalam pilihan untuk didiskusikan lebih lanjut. Karena hal inilah Partai Demokrat dan Ketua Umum Partai Susilo Bambang Yudhoyono mendapatkan protes dan kritikan. Protes dan kritikan ini juga muncul melalui media sosial seperti twitter.

Menurut Kementerian Komunikasi dan Informasi, pada tahun 2013 pengguna internet di Indonesia mencapai 63 juta orang, dan 95 persennya memanfaatkannya untuk mengakses media sosial. Dan masyarakat Indonesia merupakan pengguna twitter terbesar kelima setelah Amerika Serikat, Brazil, Jepang dan Inggris.
Dalam kasus ini, pengguna media sosial twitter menggunakan hastag \#ShameOnYouSBY untuk mengungkapkan pendapat mereka, hasilnya hampir selama 48 jam yang dimulai pada tanggal 26 sampai 28 September 2014 hastag \#ShameOnYouSBY ini bertahan menjadi trending topic di Indonesia bahkan di dunia. Hastag \#ShameOnYouSBY ini sempat hilang dari trendingtopic, dan netizen mulai membuat hastag pengganti, seperti hastag \#ShamedByYou.

Menurut Michael Delli Carpini, keterlibatan warga negara adalah tindakan individu dan kolektif yang dirancang untuk mengidentifikasi dan mengatasi masalah yang menjadi perhatian publik (Bresinger dan Chakars, 2014). Wujud dari keterlibatan warga negara ini bisa dalam berbagai macam cara, seperti pemungutan suara, melayani dalam asosiasi lingkungan dan salah satu contohnya melalui media sosial twitter dengan menggalang suara tuntutan menggunakan hastag yang sama secara bersamaan dalam satu waktu. Keterlibatan warga negara melalui media sosial ini kemudian 
semakin berkembang dan memberikan aksinya di dunia nyata.

Berbagai demonstrasi dilakukan di berbagai tempat di Indonesia bahkan di beberapa negara di dunia, seperti di Jakarta, Amerika Serikat, Paris, London, dan Hongkong, mereka mengungkapkan hal yang sama, yaitu kecewa terhadap keputusan DPR dan peran SBY sebagai kepala negara menangani RUU Pilkada.

Dari uraian tersebut "bagaimana bentuk cyber-collective action netizen melalui media sosial twitter yang menggalang dukungan dengan tagar \#ShameOnYouSBY?”

\section{Tinjauan Pustaka}

1. Pola Pandang Perkembangan Teknologi komunikasi

Dalam perkembangan teknologi komunikasi, terdapat tiga pola pandang (Silver, 2000:20-21; Wilhelm, 2000; dalam Nasrullah 2014:155) yaitu utopian, dystopian, dan tecnorealism.

1. Utopian : dalam pandangan ini, perkembangan teknologi komunikasi memberikan dampak hilangnya sekat dalam kehidupan manusia.

2. Dystopian : dalam pandangan ini, teknologi komunikasi dirasa memberikan pengaruh negatif. teknologi komunikasi seperti internet memberikan pengaruh negatif terhadap praktik komunikasi yang sebelumnya tertata secara demokratis.

3. Tecnorealism : pandangan ini menjadi pandangan yang realistis menghadapi perkembangan teknologi komunikasi. Perkembangan teknologi komunikasi dilihat sebagai sebuah revolusi media, namun revolusi yang terjadi ini tidak mengubah seluruh proses komunikasi dan struktur masyarakat.

2. Prinsip-prinsip konsumsi budaya kontemporer (dalam Jurnal Many Clicks But Little Stick : Social Media Activism In Indonesia).
Jurnal Merlyna Lim (2013) "Many Clicks But Little Stick : Social Media Activism in Indonesia" menganalisa mengenai media sosial yang mungkin mensukseskan aktivisme politik. Dengan menggunakan prinsip-prinsip konsumsi budaya kontemporer, aktivisme media sosial dimungkinkan akan berhasil mendapat dukungan massa.

1. Light package : konten yang dapat dinikmati tanpa membuang banyak waktu.

2. Headline appetite : memadatkan informasi untuk mendapatkan perhatian secara singkat.

3. Trailer vision : cerita yang disederhanakan.

\section{Civic Engangement}

Menurut Michael Delli Carpini (Addler dan Goggin : 2005) civic engagement atau keterlibatan warga negara adalah :

"Civic engagement is individual and collective actions designed to identify and address issues of public concern. Civic engagement encompasses a range of specific activities such asworking in a soup kitchen, serving on a neighborhood association, writing a letter to an elected official or voting."

Keterlibatan masyarakat merupakan tindakan individu maupun kolektif yang digunakan untuk mengatasi masalah yang sedang terjadi, dan menjadi perhatian banyak orang. Keterlibatan masyarakat ini dapat dilakukan dalam berbagai macam cara, seperti menggalang suara, memberikan pesan kepada pemimpin, mengikuti pemilu.

\section{Collective Action}

Dalam Ensiklopedi Ilmu-ilmu Sosial (2000:132) Logika tindakan kolektif oleh Mancur Olson Jr menyatakan bahwa kerjasama hanya dapat terjadi apabila setiap individu yang terlibat didalamnya memperoleh manfaat yang lebih besar dari biaya yang dikeluarkan, hitungan untung dan rugi individu lebih penting 
dibandingkan hitung rugi kelompok.

Tindakan kolektif memiliki tujuan akan adanya perubahan sosial atau suatu kelompok individu yang secara bersama mengungkapkan perasaan tidak puasnya secara kolektif di depan umum dan mengubah basis sosial dan politik yang dirasa tidak memuaskan tersebut (Eyerman \& Jamison, 1991:43-44).

Perkembangan teknologi komunikasi yang terjadi saat ini, membuat tindakan kolektif tidak hanya dilakukan secara tradisional seperti demonstrasi. Tindakan kolektif secara online telah menjadi salah satu cara masyarakat untuk menunjukkan diri, contohnya adalah kasus KPK versus Polri pada tahun 2009, dan kasus Prita Mulyasari tahun 2009. Hal ini membuat teori collective action tradisional dapat diterapkan di dunia cyber.

Dalam jurnal "Collective Action Theory Meet The Blogosphere" cyber-collective action dibagi menjadi tiga tahap, yaitu :

1. Perspektif individu : dalam tahap ini keprihatinan secara pribadi disebarkan melalui jaringan sosial yang kemudian mengakibatkan keprihatinan bersama.

2. Perspektif kelompok/masyarakat : pada tahap ini, pemimpin sebuah kelompok mempengaruhi pengikutnya, sehingga apa yang menjadi pendapat pemimpin kelompok menjadi pendapat bersama.

3. Perspektif transnasional : dalam perspektif ini, akan dibahas bagaimana kekhawatiran bersama akan menjadi kekhawatiran antar bangsa atau terhambat.

\section{Metodologi Penelitian}

Penelitian ini menggunakan bentuk deskriptifdenganpendekatankualitatif.Penelitian deskriptif bertujuan untuk mengungkapkan fakta yang akurat dan memberikan gambaran secara sistematis mengenai suatu fenomena.

Unit analisis dalam penelitian ini adalah bentuk cyber-collective action yang disampaikan melalui media sosial twitter dengan hastag \#ShameOnYouSBY dan hastag \#ShameByYou. Dan unit amatan dalam penelitian ini adalah masyarakat yang menggunakan \#ShameOnYouSBY dan \#ShameByYou di kicauan twitternya. Account twitter@Peterphwan menjadi unit amatan dalam penelitian, karena account merupakan account yang mengunggah tweetpic yang berisi undangan demonstrasi yang dilaksanakan di dua tempat di San Fransisco. @Peterphwan menjadi informan pertama dalam penelitian ini. Kemudian informan akan berkembang untuk mendapatkan data yang lebih lengkap lagi, dengan menggunakan teknik snowball sampling. Dari Informan pertama@Peterphwan mendapatkan tambahan narasumber yaitu Izak Lattu. Kemudian Izak Lattu menjadi informan kedua peneliti.

Metode pengumpulan data dalampenelitian ini menggunakan data primer dan sekunder. Data primer penulis dapatkan melalui wawancara mendalam dengan narasumber@peterphwan yang mengunggah tweetpic mengenai undangan untuk melakukan demonstrasi di dua tempat di San Fransisco menjadi narasumber. Data sekunder didapatkan melalui pengambilan tweetmengenai \#ShameOnYouSBY yang ada di twitter. Selain itu digunakan juga data sekunder yang berasal dari jurnal, buku dan data pendukung lain mengenai topik yang dibahas.

\section{Hasil Penelitian dan Pembahasan}

Dari hasil wawancara mendalam yang dilakukan secara langsung maupun melalui email dan direct message kepada informan dan analisa data sekunder yang didapatkan melalui tweet yang menggunakan hastag \#ShameOnYouSBY, didapatkan temuan data akan dibagi menjadi beberapa kategori yakni: (1) kemunculan hastag \#ShameOnYouSBY. Hastag ini muncul pertama kali pada bulan September 2014, dan sempat menjadi trending topic. Seperti yang dijelaskan olehinforman pertama@Peterphwan.

"Tagar \#shameonyouSBY sempat bertengger bbrp saat pd September 2014 di world trending topic, sebelum mendadak hilang di Twitter" 
Hastag ini merupakan aksi yang dilakukan masyarakat untuk menuntut hak demokrasi mereka. Hal ini dijelaskan oleh informan kedua Izak Lattu.

“...ShameOnYou DPR atau SBY itu dalam hal itu, adalah bentuk dari perjuangan demokrasi kami,dan sayangnya twitter waktu itu dengan menghilangkan hastag itu menurut kami twitter tidak sedang mendukung proses demokratisasi di Indonesia..."

(2) Keterlibatan Informan dengan hastag \#ShameOnYouSBY. Informan turut serta dalam penggunaan hastag \#ShameOnYouSBY baik secara online (di dunia maya) maupun offline (di dunia nyata). Dalam keterlibatanya Informan juga memiliki perspektif pribadi dalam melakukan kegiatan protes ini.

Collective action memiliki tujuan untuk membuat sebuah perubahan sosial atau menjadi suatu aksi dari rasa ketidakpuasan yang dilakukan bersama-sama (Eyerman dan Jamison, 1991:4344).

Informan pertama menggunakan hastag \#ShameOnYouSBY sebagai wujud protes dan rasa ketidakpuasannya terhadap peran SBY, serta hilangnya hak pilih warga negara Indonesia. Hal ini dijelaskan@Peterphwan mengenai tujuan dibuatnya hastag \#ShameOnYouSBY :

“...Isu penting! Saya bukan registered voter RI, tapi saya prihatin (meminjam kata2 SBY) dengan peran SBY (Partai Demokrat punya vote menentukan) yg melakukan manuver di parlemen seputar RUU Pilkada baru ini pada dasarnya merampas hak pilih langsung WNI karena Kada dipilih oleh DPRD. Padahal kita tahu kualitas sebagian anggota DPRD RI, bukan? Ini kemunduran luar biasa demokrasi di Indonesia. Hak pilih langsung WNI saya kira adalah hak sipil yg harus dipertahankan. DPR/D sudah terlalu mengklaim hak rakyat!..."

Melalui hastag \#ShameOnYouSBY informan mengungkapkan rasa keprihatinannya secara pribadi, yang kemudian dia sebarkan melalui account twitter pribadinya, sehingga orang-orang yang memiliki pemikiran dan keprihatinan yang sama ikut memberikan partisipasinya melalui hastag \#ShameOnYouSBY.

Informan kedua, Izak Lattu memberikan penjelasan yang serupa dengan informan pertama, hastag \#ShameOnYouSBY yang ada di twitter digunakan untuk menyampaikan perjuangan demokrasi masyarakat.

“...ShameOnYou DPR atau SBY itu dalam hal itu, adalah bentuk dari perjuangan demokrasi kami..."

Informan kedua juga menuangkan pendapat dan keprihatinannya ini melalui jejaring sosial facebook, email, dan membawa isu ini kedalam rapat yang ia hadiri.

“....kami rapat di Berkeley jadi ada pertemuan-pertemuan langsung, ada penggalangan informasi lewat twitter, ada ada juga apa namanya informasi disiminasi informasi lewat facebook, dan email..."

Tahap ini merupakan perspektif pribadi mengenai cyber-collective action dijelaskan dalam jurnal "Collective Action Theory Meet the Blogosphere" karya Merlyna Lim (2011). Perspektif pribadi merupakan tahap dimana keprihatinan secara pribadi disebarkan melalui jaringan sosial yang kemudian mengakibatkan keprihatinan bersama. (3) Kegiatan yang dilakukan Informan hingga hastag \#ShameOnYouSBY menjadi aksi nyata. Informan melakukan kegiatan secara nyata dengan demonstrasi dibeberapa tempat untuk menunjukkan protesnya terhadap pemerintah. Pada proses ini terdapat perspektif kelompok, dimana masyarakat yang memiliki kekhawatiran yang sama dengan pembuat hastag ikut menyebar luaskan hastag dan ikut dalam demonstrasi.

Eyerman dan Jamison (1991:43-44) menjelaskan bahwa tindakan kolektif dilakukan secara bersama di depan umum dan mengubah basis sosial dan politik yang dirasa tidak 
memuaskan tersebut. Informan pertama @ PeterPhwan mengajak masyarakat yang ada di San Fransisco USA melakukan protesnya di depan umum sebagai wujud protes terhadap keputusan pemerintah dan pertanyaan mengenai hilangnya hastag\#ShameOnYouSBY di trending topic twitter:

“.....Sangat masuk akal kalau protes ini dilakukan di San Francisco. Karena headquarter Twitter ada di San Francisco, CA! San Francisco dan Silicon Valley merupakan markas, tempat kebanyakan perusahaan teknologi komunikasi terkini dunia. Anda coba lihat di Google map, kita berada di California utara! Google, Apple, Facebook, Watsup, Instagram, Apple semuanya ada di sini! Lebih penting lagi, kita tahu bahwa tagar tadi tiba2 menghilang dari trending topic dunia. Sebagai netizen, bukankah kita berhak tahu algorithm Twitter?"

Informan juga membuat undangan untuk melakukan unjuk rasa secara nyata dan menyebarkan melalui media sosial twitter.

Tahap selanjutnya dari cybercollective action menurut jurnal Merlyna Lim (2011), "Collective Action Theory Meet the Blogosphere" adalah tahap perspektif kelompok, dimana pemimpin sebuah kelompok mempengaruhi pengikutnya, sehingga apa yang menjadi pendapat pemimpin kelompok menjadi pendapat bersama.

Informan juga melakukan tahapan yang dijelaskan tersebut dimana penyebarluasan informasi tersebut terjadi karena retweet yang dilakukan oleh para aktivis, dan hastag menjadi salah cara untuk menyampaikan isu yang ada.

“....Karena tagar mewakili isu yg hangat diwacanakan. Cuitan saya mengalami RT cukup bagus .....

....Sejumlah Aktivis Indonesia RT cuitan saya...."

Dengan pendapat yang sama dengan informan pertama, Izak Lattu sebagai informan kedua melakukan kegiatan yang sama dengan ikut bergabung dalam aksi demonstrasi yang dilakukan di headquarter twitter.

"...warga negara harus berdiri dan menyuarakan suaranya. Ini perlawanan,, menurut kami itu bentuk dari perlawanan masyarakat sipil terhadap negara. Dan menurut kami juga selain teman-teman di dalam negeri melakukan itu, kami yang di luar negeri waktu itu harus turut andil dalam proses ini, kami pikir di Amerika terutama twitter di San Fransisco, karena headquarternya di San Fransisco, kami pikir itu sangat signifikan sekali melihat isu twitter dan hastag Shame On You SBY, Shame On You DPR dan demokrasi di Indonesia."

(4) Cyber-collective action yang terjadi di Indonesia. Masyarakat Indonesia melakukan protes terhadap pemerintah dengan secara online yaitu dengan media sosial twitter dan berlanjut dengan unjuk rasa (offline) di berbagai tempat di Indonesia. Di sini terdapat pandangan baru mengenai cyber-collective action yaitu perspektif nasional. Pandangan ini melihat masyarakat yang melakukan protes terhadap kebijakan yang diputuskan pemerintah di berbagai tempat di Indonesia dan di dunia.

Pada jurnal "Collective Action Theory Meet the Blogosphere" menjelaskan mengenai kasus Saudi Women's Driving, seorang wanita yang menyampaikan pendapatnya melalui jejaring sosial karena di negaranya yang terlalu represif. Berbeda halnya dengan di Indonesia, masyarakat Indonesia meminta kembali hak pilihnya, dan menyampaikan hal tersebut melalui media twitter, kemudian mereka bersama membuat hastag \#ShameOnYouSBY menjadi trending topic, sebagai bentuk protes mereka.

Hal ini juga dijelaskan oleh penulis jurnal "Collective Action Theory Meet the Blogosphere" Merlyna Lim:
"Dalam kasus Saudi Women's
Driving itu kan memang perspektif 
komunitas itu ada dalam ranah nation-state yang bersifat represif, jadi untuk menggaungkan isu harus terfasilitasi oleh jejaring yang bersifat transnasional.

... dan tentunya perspektif nasional akan penting dalam kasus \#ShameOnYouSBY."

Melalui media sosial twitter masyarakat menuliskan aksi protesnya. Mereka menyisipkan hastag \#ShameOnYouSBY pada tweet-nya, hal ini sempat menjadi trending topic di Indonesia.

Masyarakat mengungkapkannya melalui aksi di jalanan dan mengunggahnya kembali media sosial twitter. Seluruh aksi masyarakat ini mengungkapkan hal yang sama yaitu mengenai penolakan RUU Pilkada. (5) Perkembangan hastag\#ShameOnYouSBYdigunakan secaraluas di beberapa negara. Hastag \#ShameOnYouSBY tersebarluas ke beberapa negara di dunia melalui media sosial twitter. Kekhawatiran yang dirasakan oleh masyarakat Indonesia ini terus tersebar luas ke beberapa negara termasuk oleh warga negara asing yang mengungkapkan pendapatnya dalam demonstrasi.

Tahap ketiga dari cyber-collective action menurut jurnal Merlyna Lim (2011) "Collective Action Theory Meet the Blogosphere" adalah perspektif transnasional. Dalam tahapan ini, menjelaskan bagaimana kekhawatiran yang dirasakan bersama itu menjadi kekhawatiran antar bangsa atau berhenti.

Informan pertama@Peterphwan juga menjelaskan mengenai aksi protes di beberapa negara :

“....Warga Indonesia di San Francisco bukanlah satu2nya pemrotres RUU Pilkada di dunia. Protes serupa terjadi di New York dan Washington DC. Juga, di sejumlah kota di Eropa dan Australia."

Undangan untuk melakukan demonstrasi di jalan melalui tweetpic tidak hanya muncul di San Fransisco USA, di Indonesia melakukan tindakan yang sama. Selanjutnya informan menjelaskan bahwa demonstran yang datang tidak hanya berkewarganegaraan Indonesia saja

“....ada warga Jerman kawan diaspora Indonesia yg ikut demo hari itu karena memandang isu ini penting sekali. Isu yang disuarakan hari itu adalah suara rakyat lewat Pilkada langsung harus tetap dipertahankan di RI...."

Keterangan yang sama juga diberikan oleh informan kedua Izak Lattu :

"Ada orang Belanda yang sudah lama di Amerika ikut, saya pikir ada beberapa warga negara Amerika yang ikut juga"

Tujuan mereka ikut berpartisipasi sama seperti yang disuarakan masyarakat Indonesia, mereka berpendapat bahwa demokrasi memang harus berjalan dengan baik, terutama di Indonesia:

"teman teman yang ikut waktu itu merasa bahwa Indonesia ini terutama harapan terhadap bagaimana Islam dan demokrasi bisa berjalan berbarengan itu harapannya di Indonesia."

Denganhal ini, terlihat bahwa kekhawatiran mengenai hilangnya hak pilih untuk masyarakat yang dirasakan oleh warga negara Indonesia tidak hanya menjadi kekhawatiran masyarakat Indonesia sendiri, namun dari warga negara lain pun memiliki kekhawatiran yang sama.

Kegiatan ini terjadi karena adanya tindakan individu atau secara kolektif mengenai masalah yang terjadi dan menjadi perhatian banyak orang. Menurut Michael Delli Carpini (Addler dan Goggin : 2005) keterlibatan masyarakat ini dapat dilakukan dalam berbagai macam cara, seperti menggalang suara, memberikan pesan kepada pemimpin, mengikuti pemilu.

Demonstrasi yang dilakukan warga negara Indonesia di berbagai negara menunjukkan keterlibatan masyarakat terhadap keputusan pemerintah mengenai RUU Pilkada yang telah menjadi perhatian banyak orang. (6) 
Manfaat yang didapatkan masyarakat melalui hastag \#ShameOnYouSBY. Melalui hastag \#ShameOnYouSBY di twitter masyarakat dimudahkan dalam menggalang dukungan dan menyampaikan pendapatnya. Dan dengan melakukan tindakan ini informan, dan masyarakat mendapatkan kembali hak pilih yang dituntutnya.

Dalam Ensiklopedi Ilmu-ilmu Sosial (2000:132) Logika tindakan kolektif oleh Mancur Olson Jr menyatakan bahwa kerjasama hanya dapat terjadi apabila setiap individu yang terlibat didalamnya memperoleh manfaat yang lebih besar dari biaya yang dikeluarkan, hitungan untung dan rugi individu lebih penting dibandingkan hitung rugi kelompok.

Manfaat yang dirasakan jika demonstrasi ini bisa ditanggapi dengan baik adalah kembalinya hak pilih masyarakat yang telah menjadi kepentingan bersama. Seperti yang dijelaskan informan pertama @Peterphwan :

“...hak memilih (voting) adalah hak hakiki yang harus diperjuangkan dalam sistem demokrasi. Ini soal maha penting agar suara rakyat tidak dimanipulasi DPR/D yang mengklaim sbg wakil rakyat....

....Ada kepuasan kolektif jika concern bersama ini bisa tercapai! Jadi, kewarganegaraan, keanggotaan dalam partai/ Pemilu tidak relevan."

Bagi informan kedua Izak Lattu, manfaat setelah melakukan demonstrasi ini adalah munculnya kebijakan baru yang mengembalikan hak pilih kepada rakyat.

"Saya pikir dengan adanya kebijakan kebijakan baru lagi terutama di era jokowi dengan mengembalikan pemilihan langsung kepada rakyat lagi, menurut kami tekanan kami sudah berhasil..."

Peran media sosial dalam pembentukan cyber-collective action. Informan menggunakan media sosial seperti twitter, google plus, dan facebook, untuk menggalang dukungan dan partisipasi masyarakat dan warga negara
Indonesia. CMC merupakan proses komunikasi manusia dengan media komputer yang melibatkan khalayak, dalam hal tertentu, dan memanfaatkan media untuk suatu tujuan (Desember, 1997 : dalam Nasrullah 2014:78).

Informan pertama menggunakan media sosial untuk berkomunikasi, dan memiliki tujuan untuk menggalang partisipasi warga negara indonesia.

"Kebanyakan Warga Indonesia di California utara yang ikut protes adalah pengguna Facebook dan pemilik akun Gmail. Media lain dipakai untuk menggalang partisipasi warga dalam protes. Juga, dipakai untuk menyampaikan siaran pers pasca protes..."

Informan kedua juga menjelaskan mengenai beberapa media sosial yang digunakan untuk menggalang dukungan.

"Kita pakai twitter juga, kita pakai facebook, kita pakai email...

...ada penggalangan informasi lewat twitter, ada ada juga apa namanya informasi disiminasi informasi lewat facebook, dan email"

Lebih lanjut informan menjelaskan seberapa kuat peran media sosial untuk menggalang dukungan tersebut.

"melalui media sosial, media sosial memang sangat kuat sekali untuk penggalangan itu.."

Pandangan Informan terhadap perkembangan teknologi komunikasi. Dalam menggunakan teknologi komunikasi informan termasuk dalam kelompok tecnorealism, karena informan menggunakan media sosial tanpa meninggalkan cara lama dalam berpendapat melalui unjukrasa.

Terdapat 3 pandangan dalam menerima perkembangan teknologi komunikasi, yaitu utopian, dystopian dan tecnorealism. Dari wawancara yang dilakukan, peneliti menemukan para informan memiliki pandangan tecnorealism dalam menerima perkembangan teknologi komunikasi. 
Tecnorealism adalah pandangan yang realistis menghadapi perkembangan teknologi komunikasi. Dalam hal ini perkembangan teknologi komunikasi dilihat sebagai sebuah revolusi media, namun revolusi yang terjadi ini tidak mengubah seluruh proses komunikasi dan struktur masyarakat (Wilhelm, 2000;23; dalam Nasrullah 2014:157).

Dalam wawancaranya, informan pertama @ Peterphwan memberikan informasi mengenai media yang digunakan dalam menyebarluaskan pesan, serta memberikan tindakan nyata dalam melakukan demonstrasi di depan umum:

"...via twitter dan silaturahmi langsung, saya berdiskusi dengan sesama aktivis. Mulai dari penggiat soal kebebasan berpendapat di dunia digital, awak pers Indonesia di AS dan akademisi UC Berkeley"

Lebih lanjut@Peterphwan menjelaskan mengenai tindakan yang dilakukan secara langsung terkait dengan demonstrasi yang diadakan di San Fransisco.

“...Sebagian peserta demo di SF, baik di depan Twitter HQ dan di depan kantor Konsulat Jendral RI di SF, datang dengan sukarela karena undangan yg kita sebarkan via social media..."

Sama halnya dengan informan pertama, informan kedua Izak Lattu juga melakukan tindakan yang sama dalam menggalang dukungan dan melakukan aksinya di San Fransisco.

"Kita pakai twitter juga, kita pakai facebook, kita pakai email, biasa, ada juga rapat-rapat yang kita lakukan di Berkeley terutama, jadi di awal itu kita aksi di San Fransisco tapi kita rapatnya di Berkeley waktu itu"

Dalam menggalang dukungan ia menggunakan media sosial, namun untuk aksi selanjutnya, informan melakukan demonstrasi secara langsung untuk menyampaikan pendapatnya.

(9) Aktivisme media sosial dengan menggunakan prinsip konsumsi budaya kontemporer. Hastag \#ShameOnYouSBY bisa sukses menjadi trending topic dan digunakan masyarakat karena adanya konsumsi budaya kontemporer seperti yang dijelaskan dalam jurnal Merlyna Lim (2013) "Many Clicks but little stick: Social Media Activism in Indonesia" untuk mensukseskan aktivisme di media sosial diperlukan prinsip-prinsip konsumsi budaya kontemporer yakni :

- Light package : konten yang dapat dinikmati tanpa membuang banyak waktu.

- $\quad$ Headline appetite :memadatkan informasi untuk mendapatkan perhatian secara singkat.

Trailer vision : cerita yang disederhanakan.

Sebanyak $85 \%$ dari total pengguna internet di Indonesia mengakses internet menggunakan mobile phone. Dalam jurnal Merlyna Lim (2013) "Many Clicks But Little Stick: Media Sosial Activism in Indonesia" menjelaskan mereka yang menggunakan mobile phone narasi yang sederhana untuk menjadi viral, hal ini meniru budaya populer yang telah ada sebelumnya.

Dalam kasus hastag \#ShameOnYouSBY dibingkai menjadi cerita yang sederhana. Shame on you dalam bahasa Indonesia memiliki arti kata malu pada diri anda. Sehingga Shame on you SBY dapat diartikan menjadi malu pada diri anda SBY. Kemudian muncul gambar-gambar SBY dengan tulisan protes didalamnya. Salah satunya adalah gambar SBY dengan tulisan "Bapak Pilkada tidak langsung Indonesia".

Dalam kamus besar bahasa Indonesia, bapak adalah orang yang menjadi pelindung (pemimpin, perintis jalan, dan sebagainya yang banyak penganutnya). Hal ini diterapkan dalam gambar tersebut, dimana SBY mejadi orang yang memimpin adanya pilkada tidak langsung.

Kemudian muncul gambar lain yang menggambarkan kekecewaan masyarakat melalui media sosial twitter. Bahkan para artis ibukota membuat lagu yang diunggah 
ke youtube dengan judul "Where Are You Mr President?" hal ini membantu terbentuknya trailer vision dalam kasus \#ShameOnYouSBY.

Aktivitas yang dilakukan masyarakat dalam kasus ini memiliki resiko yang kecil, dengan mengunggah tweet mengenai RUU Pilkada dan \#ShameOnYouSBY telah memberikan penjelasan mengenai kasus yang terjadi.

Masyarakat yang turun ke jalan pun tidak sebanyak kicauan yang didapatkan, hanya sedikit orang yang mau mengambil resiko yang lebih besar dengan bergabung ke jalanan.

\section{Refleksi hasil penelitian}

Dari analisis yang telah dilakukan tersebut, maka dapat diketahui bahwa hastag \#ShameOnYouSBY yang digunakan di twitter merupakan tagar yang memuncaki trending topic dunia pada bulan September tahun 2014 dan kemudian hilang.

Hastag \#ShameOnYouSBY ini dibuat sebagai wujud protes dan rasa ketidadkpuasannya terhadap peran SBY, serta hilangnya hak pilih warga negara Indonesia. Media yang masyarakat pakai untuk menunjukkan rasa ketidakpuasannya adalah melalui media sosial twitter. Aksi kolektif ini dilakukan melalui media sosial twitter, sehingga hastag \#ShameOnYouSBY ini menjadi trending topic dunia.

Melalui media sosial twitter pula protes yang dilakukan masyarakat ini berkembang menjadi aksi nyata demonstrasi di jalanan. Dengan hastag \#ShameOnYouSBY sebagai pembahasan yang berkembang di twitter undangan untuk melakukan demonstrasi di depan umum pun disebar melalui media sosial ini. Masyarakat pun menanggapi hal tersebut dan ikut bergabung dengan kegiatan tersebut, kemudian mereka kembali menyebarkan foto kegiatan demonstrasi melalui twitter.

Dalam demonstrasi yang dilakukan ini tidak hanya warga negara Indonesia saja yang terlibat didalamnya, ada orang asing atau bukan warga negara Indonesia yang ikut bergabung dalam kegiatan ini. Mereka yang melakukan kegiatan ini berpendapat bahwa hak untuk pilih merupakan hak bagi warga negara dengan sistem demokrasi.

Manfaat yang didapatkan melalui collective action dengan hastag \#ShameOnYouSBY ini adalah kembalinya hak pilih masyarakat. Dengan kegiatan yang dilakukan dari media sosial twitter menjadi kegiatan yang dilakukan di depan umum akan menjadi kepuasan yang dirasakan bersama jika tujuan dari dibuatnya kegiatan ini tercapai.

Melalui media sosial pula, masyarakat dimudahkan dalam berkomunikasi, sehingga dukungan yang didapatkan menjadi lebih luas, terlihat dari partisipan yang bergabung dalam demonstrasi tidak hanya aktivis yang sering berinteraksi sebelumnya.

“....Sebagian peserta demo di SF, baik di depan Twitter HQ dan di depan kantor Konsulat Jendral RI di SF, datang dengan sukarela karena undangan yg kita sebarkan via social media. Bahkan ada demonstran yg baru kita kenal saat demonstrasi. Percaya atau tidak, ada warga Jerman kawan diaspora Indonesia yg ikut demo hari itu karena memandang isu ini penting sekali...."

Media sosial menjadi sebuah media yang membantu dalam penggalangan dukungan masyarakat, dengan media sosial pula masyarakat saling berkomunikasi. Dengan melakukan retweet dan menyebarkan informasi melalui media sosial menjadi sebuah interaksi yang terjadi antara pengguna media.

Dalam jurnal "Collective Action Theory Meets the Blogosphere" cyber-collective action dibagi menjadi 3 tahap :
1. Tahap perspektif individu
2. Tahap perspektif masyarakat/kelompok
3. Tahap perspektif transnasional 


\begin{tabular}{|c|c|c|}
\hline Perspektif Individu & Perspektif masyarakat & Perspektif transnasional \\
\hline $\begin{array}{l}\text { Informan membagikan } \\
\text { kekhwatirannya } \\
\text { mengenai hak pilih } \\
\text { Pilkada yang berada di } \\
\text { DPRD melalui media } \\
\text { sosial twitter dengan } \\
\text { meggunakan hastag } \\
\text { \#ShameOnYouSBY. } \\
\text { Undangan demonstrasi } \\
\text { yang dilakukan didepan } \\
\text { umum juga disebar } \\
\text { melalui media sosial } \\
\text { twitter. }\end{array}$ & $\begin{array}{l}\text { Hastag \#ShameOnYouSBY } \\
\text { ini kemudian disebarluaskan } \\
\text { kembali oleh masyarakat. } \\
\text { Masyarakat yang merasa } \\
\text { haknya diambil oleh } \\
\text { pemerintah dengan } \\
\text { keputusan sahnya undang- } \\
\text { undang Pilkada ini } \\
\text { kemudian me-retweet } \\
\text { unggahan dari informan dan } \\
\text { para aktivis yang akan } \\
\text { melakukan aksi } \\
\text { demonstrasi, dan } \\
\text { menuliskan kekhawatiran } \\
\text { yang sama melalui media } \\
\text { sosial twitter. }\end{array}$ & $\begin{array}{l}\text { Hastag \#ShameOnYouSBY ini } \\
\text { menjadi trending topic dunia karena } \\
\text { kerjasama yang dilakukan } \\
\text { masyarakat. Kemudian demonstrasi } \\
\text { yang dilakukan oleh warga negara } \\
\text { Indonesia tidak hanya terjadi di } \\
\text { Indonesia saja, namun di berbagai } \\
\text { negara di Indonesia. Partisipan yang } \\
\text { ikut melakukan aksi ini tidak hanya } \\
\text { warga negara Indonesia, namun ada } \\
\text { warga negara asing seperti warga } \\
\text { negara Jerman, Belanda, dan } \\
\text { Amerika, yang ikut bergabung dalam } \\
\text { demonstrasi. Kepentingan yang } \\
\text { diungkapkan dalam demonstrasi } \\
\text { yang dilakukan pun sama, yaitu hak } \\
\text { pilih yang diberikan untuk rakyat } \\
\text { sebagai negara demokrasi. } \\
\text { Aksi mereka ini kemudian diunggah } \\
\text { melalui media sosial twitter. }\end{array}$ \\
\hline
\end{tabular}

Dalam penelitian ini, ditemukan satu pandangan yang belum ada dalam pembahasan sebelumnya dalam jurnal "Collective Action Theory Meets the Blogosphere" yaitu perspektif nasional. Dalam perspektif nasional, masyarakat memiliki pandangan yang sama mengenai RUU Pilkada, mereka menolak RUU Pilkada tersebut, karena dengan sahnya RUU ini akan membuat hak pilih masyarakat sebagai warga negara hilang. Hal ini ditunjukkan oleh demonstrasi yang dilakukan masyarakat di berbagai wilayah, seperti di Jakarta, Malang, Bandung, Bogor dan Balikpapan.

Masyarakat Indonesia memiliki kekhawatiran yang sama dengan munculnya RUU Pilkada, hingga akhirnya muncul hastag \#ShameOnYouSBY, dan menjadi trending topic di Indonesia dan dunia. Selain melakukan protes melalui dunia maya, masyarakat Indonesia juga melakukan demonstrasi secara langsung di berbagai daerah di Indonesia sebagai bentuk penolakan RUU Pilkada. Pandangan masyarakat ini yang kemudian menjadi pandangan nasional dalam menghadapi RUU Pilkada.

Dilihat dari cara informan melakukan gerakan dan aksi untuk mencapai tujuannya,pola pandang yang terjadi terhadap perkembangan teknologi adalahtechnorealism. Karenainforman melakukan demonstrasi serta mencaripendukung melalui media sosial twitter yang menjadi salah satu bentuk baru dari aksi kolektif yaitu cybercollective action, dan selanjutnya melakukan demonstrasi di depan umum yang menjadi cara tradisional dalam melakukan collective action. Dalam pandangan technorealism menjelaskan bahwa perkembangan media komunikasi tidak mengubah seluruh proses komunikasi dalam struktur yang telah dibangun masyarakat sebelumnya.

Untuk menggalang dukungan massa melalui media sosial, terdapat prinsip konsumsi budaya kontemporer yaitu light package, headline appetite, dan trailer vision. Peneliti menemukan prinsip tersebut dalam tweet yang diunggah oleh informan 1, Peter Phwan. Ia mengunggah undangan beserta waktu 
pelaksanaan dalam satu waktu, dan dalam undangannya ia menuliskan alasan dilakukan demonstrasi secara singkat.

\section{Penutup}

Dalam penelitian ini terdapat beberapa temuan yaitu: (1) Hastag \#ShameOnYouSBY merupakan hastag yang sempat menjadi trending topic dunia. (2) hastag ini dibuat untuk menunjukkan protes masyarakat terhadap pemerintah akibat dikeluarkannya RUU Pilkada. (3) Masyarakat menuliskan kicauannya melalui media sosial twitter dan mengunggah undangan demonstrasi secara langsung dibeberapa tempat. (4) Di Indonesia protes dilakukan melalui media sosial twitter dengan hastag \#ShameOnYouSBY, dan trending topic selama beberapa hari. (5) hastag \#ShameOnYouSBY terus meluas hingga ke berbagai negara, dan warga asing turut serta dalam protes atas kebijakan pemerintah tersebut. (6) Protes ini akhirnya mengembalikan hak masyarakat dalam memilih dengan dibuatnya kebijakan baru. (7) media sosial memiliki peran yang penting dalam menyebarluaskan pesan dan protes yang dilakukan. (8) masyarakat dalam hal ini memiliki pandangan tecnorealism, mereka masih melakukan protes dengan turun ke jalan, walaupun telah menuliskan protes melalui media sosial. (9) Untuk menarik masyarakat melakukan protes, para aktivis media sosial menggunakan prinsip konsumsi budaya kontemporer yaitu : light package, headline appetite, dan trailer vision.

Dalam penelitian ini tahapan cyber collective action yaitu (1) perspektif individu, (2) perspektif masyarakat, (3) perspektif nasional, (4) perspektif transnasional.

\section{Saran}

Berdasarkan penelitian yang telah dilakukan ini, maka saran yang dapat diberikan sebagai berikut :

1. Untuk penelitian selanjutnya, dapat meneliti mengenai terbentuknya hastag \#ShameOnYouSBY dengan mewawancarai pembuat pertama hastag, tambahan narasumber pengguna hastag \#ShameOnYouSBY in akan membuat penelitian ini semakin kaya.

2. Menggunakan metode penelitian dengan sudut pendang politis, sosial, budaya dan penggerak bagi masyarakat.

\section{Daftar Pustaka}

\section{Buku}

Effendy, Onong Uchyana. 1999. Ilmu Komunikasi : Teori dan Praktek. Bandung : PT. Remaja Rosdakarya.

Eriyanto. 2011. Analisis Isi : Pengantar Metodologi Untuk Penelitian Ilmu Komunikasi dan Ilmu-ilmu Sosial Lainnya. Jakarta : PT Fajar Interpratama Mandiri.

Kuper, Adam dan Jessica. 2000. Ensiklopedi : Ilmu-Ilmu Sosial . Jakarta : PT. Raja Grafindo Persada.

Lexy Moelong. 2006. Metodologi Penelitian kualitatif. $\quad$ Bandung: Remaja Rosdakarya.

Nasrullah, Rulli. 2014. Teori dan Riset Media Siber (cybermedia). Jakarta : Kencana Prenada Media Grup.

Suharko. 2006. Gerakan Sosial : Konsep, Srategi, Aktor. Hambatan dan Tantangan Gerakan Sosial di Indonesia. Malang : Program Penguatan Simpul Demokrasi Kab. Malang.

Sztompka, Piötr. 2007. Sosiologi Perubahan Sosial. Jakarta : Prenada.

\section{Jurnal}

Agarwal, Nitin., Lim, Merlyna., Wigand, Rolf T. 2011. Collective Action Theory Meets the Blogosphere: A New Methodology.

Lim, Merlyna. 2013. Many Clicks but Little Sticks: Social Media Activism in Indonesia. 


\section{Internet}

Bint005. (2013, 7 November). Kominfo : Pengguna Internet di Indonesia 63 Juta Orang. Kemenkominfo (On-Line). Diakses pada 07 Juni 2015, pukul 22:12. http://kominfo.go.id/index.php/content/ detail $/ 3415 /$ Kominfo $+\% 3 \mathrm{~A}+$ Pengguna + Internet $+\mathrm{di}+$ Indonesia $+63+$ Juta+Ora ng/0/berita satker\#.VMZuzD8xXIt

BH, Arifin. (2014, 10 Februari). Pengguna Twitter Indonesia Terbanyak Ketiga Dunia. Encienty.co. Diakses pada 09 September 2015, pukul 21.14. http:// www.enciety.co/pengguna-twitterindonesia-terbanyak-ketiga-dunia/ http://www.apjii.or.id/v2/read/content/ info-terkini/301/pengguna-internetindonesia-tahun-2014-sebanyak-88. html diakses pada tanggal 07 Juli 2015 pukul 06:27.

Subekti. (2014, $28 \quad$ September). \#ShameOnYouSBY Hilang, Muncul \#ShamedByYou. Tempo. Diakses pada 09 Maret 2015, pukul T12:48. http://www.tempo.co/ read/news/2014/09/28/07861071/ ShameOnYouSBY-Hilang-MunculShameByYou 